Abstracta Iranica Abstracta Iranica

Revue bibliographique pour le domaine irano-aryen

Volume 29 | 2008

Comptes rendus des publications de 2006

\title{
Eurasian Studies [Liber Amicorum : Études sur l'Iran médiéval et moderne offertes à Jean Calmard]. Vol. V/ 1-2, 2006, XVI-392 p., planches.
}

\section{Rédaction}

\section{(2) OpenEdition}

\section{Journals}

Édition électronique

URL : http://journals.openedition.org/abstractairanica/23282

DOI : 10.4000/abstractairanica.23282

ISSN : 1961-960X

Éditeur :

CNRS (UMR 7528 Mondes iraniens et indiens), Éditions de l'IFRI

\section{Édition imprimée}

Date de publication : 15 mai 2008

ISSN : 0240-8910

Référence électronique

Rédaction, «Eurasian Studies [Liber Amicorum : Études sur l'Iran médiéval et moderne offertes à Jean Calmard]. Vol. V/1-2, 2006, XVI-392 p., planches. », Abstracta Iranica [En ligne], Volume 29 | 2008, document 6, mis en ligne le 15 septembre 2008, consulté le 26 septembre 2020. URL : http:// journals.openedition.org/abstractairanica/23282 ; DOI : https://doi.org/10.4000/abstractairanica. 23282

Ce document a été généré automatiquement le 26 septembre 2020.

Tous droits réservés 


\title{
Eurasian Studies [Liber Amicorum: Études sur l'Iran médiéval et moderne offertes à Jean Calmard]. Vol. V/1-2, 2006, XVI-392 p., planches.
}

\author{
Rédaction
}

1 Dans ce volume offert en hommage à Jean Calmard, on trouvera des articles traitant de sujets très variés, mais tournant tous autour des thèmes de prédilection de son destinataire : l'histoire de l'Iran, essentiellement à l'époque safavide avec, également, des incursions dans d'autres époques, timouride entre autres. La plupart des articles sont recensés dans le présent numéro.

2 Les articles sont classés par ordre alphabétique des auteurs : ainsi, après les pages d'introduction, le lecteur trouvera : Iraj Afshar : « Un document à propos du commerce de l'opium iranien en Chine » (pp. 1-3) (cf. c.r. $\left.\mathrm{n}^{\circ} 174\right)$; Denise Aigle : « La légitimité islamique des invasions de la Syrie par Ghazan Khan » (pp. 5-29) (cf. c.r. $n^{\circ} 143$ ) ; JeanLouis Bacqué-Grammont : «Glissements progressifs du fantastique. Quelques exemples safavides et ottomans » (pp. 31-53) (cf. c.r. $n^{\circ}$ 176) ; Michele Bernardini : « À propos du vatan timuride » (pp. 55-67) (cf. c.r. $\mathrm{n}^{\circ}$ 148) ; Peter Chelkowski : « Shared affinities: hoseynīyes and emāmbāres» (pp. 69-78) (cf. c.r. $n^{\circ}$ 285) ; Ehsan Echraqi : «Les alentours du Palais du Gouvernement safavide à Qazvin dans les poèmes de "Abdī Beg Navīdī " (pp. 79-91) (cf. c.r. $n^{\circ}$ 179) ; Hossein Esmaili : « Les éléments scéniques du ta'ziye : statut et sens » (pp. 93-105); Willem Floor : « The import of Indian textiles into Safavid Persia » (pp. 107-42) (cf. c.r. n 182) ; Marina Gaillard : « Du 'ayyār au šățer : l'évolution du personnage à travers le roman persan en prose » (pp. 143-173) (cf. c.r. n 322) ; Masashi Haneda : "Les compagnies des Indes orientales et les interprètes de Bandar "Abbās " (pp. 175-193) (cf. c.r. $\mathrm{n}^{\circ}$ 187) ; Rudi Matthee : « A sugar banquet for the Shah: AngloDutch competition at the Iranian court of Šāh Sulțān Ḥusayn (r. 1694-1722)» (pp. 195-217) (cf. c.r. $\left.n^{\circ} 198\right)$; Charles Melville : « Ibn Husām's Hुāvarān-nāma and the Šāhnāma of Firdawsī » (pp. 219-233) (cf. c.r. n 333) ; Irine Natchkebia : «General Gardane 
and the members of his mission on Persia in the context of the Indian expedition (1807-1809)» (pp. 235-255) (cf. c.r. $\mathrm{n}^{\circ}$ 202) ; Andrew J. Newman : « The vezir and the mulla: a late Safavid period debate on Friday prayer» (pp. 237-269) (cf. c.r. $n^{\circ} 204$ ) ; Angelo Michele Piemontese : "Les célébrites du Janicule et les diplomates safavides immigrés à Rome » (pp. 271-295) (cf. c.r. n 205) ; Yann Richard : « Le journal d'Hélène Hoppenot : une source inédite sur le coup d'État de $1921 »$ (pp. 297-305) (cf. cr. n²29) ; Biancamaria Scarcia Amoretti : "Rethinking the Šì questions » (pp. 307-317) (cf. c.r. ${ }^{\circ}$ 207) ; Mansur Sefatgol : « Persian historical writing under the last Safavids: the historiographers of decline» (pp. 319-331) (cf. c.r. $n^{\circ} 208$ ) ; Maria Szuppe : "Notes sur l'historiographie indo-persane : une "chronique » en chronogrammes de 'Abdallāh Kābolī (ca. 990/1582)» (pp. 333-356) (cf. c.r. n 221) ; Luís Filipe Thomaz : « $\mathrm{H}^{\mathrm{w}}$ āje Pīr Qolī et sa Brève relation de la Perse » (pp. 357-369) (cf. c.r. $\mathrm{n}^{\circ}$ 212); Živa Vesel : « Note sur l'iconographie shiite populaire " (pp. 371-375) (cf. c.r. $\mathrm{n}^{\circ}$ 287); Akihiko Yamaguchi : " A note on fruit cultivation in the early eighteenth century Hamadān province » (pp. 377-392) (cf. c.r. n 215).

\section{INDEX}

Thèmes : 1.2. Recueils d'articles : revues, colloques, ouvrages collectifs

\section{AUTEURS}

RÉDACTION

Directeur de la revue et secrétariats (Paris et Téhéran) 